\title{
PRESCRIBING PATTERN IN GERIATRIC PATIENTS IN MEDICAL OPD OF A TERTIARY CARE TEACHING HOSPITAL
}

\author{
KANIKA KHAJURIA ${ }^{1}$, VIJAY KHAJURIA ${ }^{2 *}$
}

${ }^{1}$ Department of Pharmacology, Government Medical College, Jammu, Jammu and Kashmir. ${ }^{2}$ Department of Pharmacology, Government Medical College, Jammu, Jammu and Kashmir. Email: vijayhaj@yahoo.co.in

Received: 10 February 2021, Revised and Accepted: 28 March 2021

\section{ABSTRACT}

Objectives: Geriatric population is increasing globally and they suffer from multiple disorders necessitating administration of number of drugs. The objective of the present study was to examine the prescribing pattern in geriatric patients in a medical OPD.

Methods: An observational, cross-sectional study was conducted in medical OPD of Government Medical College, Jammu, over a period of a month after approval of the Institutional Ethics Committee. Patients above 65 years of age who gave consent were included in the study. The prescriptions were analyzed for demographic profile (age and gender), average number of drugs per prescription, drugs by generic or brand names, fixed drug combinations (FDCs), and percentage of potentially inappropriate as per Beers criteria.

Results: A total of 200 patients were included comprised $64 \%$ of males and $36 \%$ of females. The most of patients were in the age group of $65-69$ years (37.5\%). A total of 200 prescriptions contained 1128 drugs amounting to average 5.64 number of drugs per prescription. Maximum prescriptions had 1-5 drugs (61\%) followed by 6-10 drugs (38.5\%). Majority of drugs were prescribed by brand name (93.26\%) and only 6.73\% of drugs were prescribed by generic name. About 10.46\% FDCs were prescribed. Maximum drugs prescribed were from respiratory system (20.3.1\%), followed by GIT (18.4\%), antimicrobials (17.2\%), cardiovascular (10.99\%), NSAIDs (9.3\%), and vitamins (8.4\%). Forty-one drugs (20.5\%) in patients were potentially in appropriate drugs based Beers criteria and belonged mostly to anticholinergic, antihistaminic, sedatives, NSAIDs, and H2 blockers.

Conclusions: The present study demonstrates that polypharmacy and potentially inappropriate medication are still present in OPD prescription of geriatric population. Generic prescribing still lacks. Application of Beers criteria and increasing awareness about polypharmacy should be encouraged.

Keywords: Geriatric, Prescribing pattern, Polypharmacy, Beers criteria.

(C) 2021 The Authors. Published by Innovare Academic Sciences Pvt Ltd. This is an open access article under the CC BY license (http://creativecommons.org/ licenses/by/4.0/) DOI: http://dx.doi.org/10.22159/ajpcr.2021v14i5.41065. Journal homepage: https://innovareacademics.in/journals/index.php/ajpcr

\section{INTRODUCTION}

Treatment of elderly patients constituting above 65 years of age is always a challenge to the attending physician. It stems from the fact that there are multiple comorbidities in this age group warranting management with multiple drug regimens. Polypharmacy exposes them to likelihood of potentially inappropriate medications (PIMs), drug interactions, adverse drug reactions, and poor compliance. The alterations in physiological functions due to aging and inadequate monitoring further make the situation complex.

Due to advances made in medical field coupled with improvement in socioeconomic status, there is increase in life expectancy. The world population is growing and so is the elderly aged group. The world's elderly population which was 550 million in 1996 is expected to approach 1.2 billion by the year 2025 [1]. Although it much evident in developed countries, India is also no exception. It is projected that the proportion of Indians aged 60 and older will rise from $7.5 \%$ in 2010 to $11.1 \%$ in 2025 [2]. Projected life expectancy in India by 2025 is 69.8 years for males and 72.3 years for females.

With increase in geriatric population, there is always associated risk of polypharmacy [3]. Although the overall elderly population percentage is less than other age groups, still they consume large amount of drugs. According to one estimate, people with age of 65 years or more forms $12 \%$ of the U.S. population, but they account for use of $34 \%$ of all prescription medication and $30 \%$ of all over-the-counter medication [4]. About $44 \%$ of men and $57 \%$ of women older than 65 years take five or more non-prescription or prescription medications per week, and $12 \%$ take 10 or more medications per week [5].
The polypharmacy and inappropriate prescribing are major issues in elderly population. Polypharmacy continues to increase and is a known risk factor for morbidity and mortality [6]. Beers in 1991 to decrease inappropriate prescribing and adverse drug events came out with Beers criteria to identify medications those should be avoided in older adults. After Beer's death, the American Geriatrics Society supervises and revises the criteria and provides updates every 3 years, with latest updates appearing in 2019 [7]

Inappropriate medication if detected early can prevent adverse reactions. Since elderly population is more vulnerable to adverse effects, so it is of utmost importance that they are evaluated for PIM. Therefore, the present study was conducted to analyze the prescribing pattern in elderly patients attending medical outpatient department of a tertiary care teaching hospital.

\section{METHODS}

The present prospective, cross-sectional, observational study was conducted in medical OPD of Government Medical College, Jammu, over a period of a month. The permission from the Institutional Ethic Committee (IEC) was obtained before the start of the study vide number IEC/2018/571, dated September 29, 2018. Prescription of 200 patients attending medical OPD was analyzed who full filled following criteria.

\section{Inclusion criteria}

Patients of 65 years of age or above and willing to give informed consent were included in the study.

\section{Exclusion criteria}

All patients below 65 years of age and unwilling to participate were excluded from the study. The prescriptions were clicked on mobile 
and were analyzed for demographic profile (age and gender), average number of drugs per prescription, drugs by generic or brand names, injectable, FDCs, and percentage of drugs inappropriate as per Beers criteria [7].

\section{Statistical analysis}

Results are presented as mean number and percentage.

\section{RESULTS}

A total of 200 patients prescriptions were included for analysis and most of patients were in the age group of 65-69 years (37.5\%). One hundred and twenty-eight patients were male (64\%) and 72 patients were female (36\%) (Table 1).

A total of 200 prescriptions contained 1128 drugs, amounting to average 5.64 number of drugs per prescription. Maximum prescriptions had 1-5 drugs prescribed (61\%) followed by 6-10 drugs (38.5\%) (Table 2). Majority of drugs were prescribed by brand name (93.26\%) and only $6.73 \%$ of drugs were prescribed by generic name. About $10.46 \%$ FDCs were prescribed (Table 3). Maximum drugs prescribed were from respiratory system (20.31\%), followed by GIT (18.4\%), antimicrobials (17.2\%), cardiovascular (10.99\%), NSAIDs (9.3\%), vitamins (8.4\%), and endocrine system (7.9\%) (Table 4). Forty-one drugs $(20.5 \%)$ in patients were potentially inappropriate drugs based Beers criteria and belonged mostly to antispasmodic/anticholinergic (belladonna alkaloids, clidinium, and dicyclomine), antihistaminics (chlorpheniramine, cyproheptadine, dexchlorpheniramine, and diphenhydramine), sedatives (chlordiazepoxide and diazepam), NSAID (piroxicam), and $\mathrm{H} 2$ blockers (ranitidine) (Table 5).

\section{DISCUSSION}

Geriatric group is most vulnerable to adverse effects of drugs primarily because they consume in large number of drugs. The current study was done to examine the prescribing pattern of drugs in elderly patients attending medical OPD. Polypharmacy is closely linked with inappropriate medication which further expose to economic burden and chances of ADRs.

The present study has shown that most of patients reporting were male $(64 \%)$. Most of the patients were in the age group of 65-74 years (73.5\%), while 65-69 years group alone contributed $37.5 \%$, similar to

Table 1: Demographic profile of patients

\begin{tabular}{lllll}
\hline $\begin{array}{l}\text { Age in } \\
\text { years }\end{array}$ & $\begin{array}{l}\text { Number of } \\
\text { patients }\end{array}$ & $\begin{array}{l}\text { Number of } \\
\text { male patients }\end{array}$ & $\begin{array}{l}\text { Number of } \\
\text { female patients }\end{array}$ & Percentage \\
\hline $65-69$ & 75 & 40 & 35 & 37.5 \\
$70-74$ & 72 & 51 & 21 & 36.0 \\
$75-79$ & 48 & 34 & 14 & 24.0 \\
$>80$ & 5 & 3 & 2 & 2.5 \\
Total & 200 & $128(64 \%)$ & $72(36 \%)$ & \\
\hline
\end{tabular}

Table 2: Number of drugs prescribed as per prescription

\begin{tabular}{lll}
\hline Number of drugs & Number of prescription & Percentage \\
\hline $1-5$ & 122 & 61.0 \\
$6-10$ & 77 & 38.5 \\
$10-14$ & 01 & 0.5 \\
$>14$ & 0 & 0 \\
\hline
\end{tabular}

Table 3: Distribution of drugs as generic, brand, and FDCs

\begin{tabular}{lll}
\hline Drugs & Number of drugs & Percentage \\
\hline Generic & 76 & 6.73 \\
Brand & 1052 & 93.26 \\
Fixed drug combinations & 118 & 10.46 \\
\hline
\end{tabular}

our observation, a study has also reported $68.0 \%$ of OPD patients were between 65 and 74 years [8].

Analysis of the prescriptions revealed that majority of them had 1-5 drugs (61\%), while 6-10 drugs were prescribed in $38.5 \%$ of prescriptions. Average number per prescription was 5.64. Another study has also observed $5.50 \pm 2.8$ drugs per prescription [9].

Most of these drugs were prescribed by brand name (93.26\%) while generic only accounted for $6.73 \%$. This underscores that still brand pharmaceuticals are preferred over generic. This is a matter of concern and needs to be addressed as brand adds to economic burden on patients. At present, Prime Minister's Jan Aushadhi outlets are destined to change the scenario but hospital pharmacy also needs to be strengthened. Strict regulations ensuring bioequivalence standard of drugs will further boost confidence in generic drugs.

About 10.46\% FDCs were found prescribed in the present study. Most these were analgesic combinations followed antimicrobials. Similar to our results, FDCs use of $10.82 \%$ has have been reported in recent past [10].

FDCs are popular as they lead to improved compliance and decrease pill burden. However, FDC is pharmacologically acceptable only if the combination has a proven therapeutic and safety advantage over single ingredients administered separately and should act by different mechanisms and have additive effects. However, FDCs cause unnecessary prolonged exposure and are reported to be responsible for a causing more ADRs that single drugs [11]. Therefore, the use of FDCs in geriatric group demands more caution as this group is more prone to ADRs because of declined physiological functions.

Research workers have demonstrated that polypharmacy is a big issue in geriatric population. There is no consensus definition for polypharmacy but most commonly term is applied with use of five or more drugs used daily by an individual [12]. Whereas, the World Health Organization defined polypharmacy as "the administration of many drugs at the same time or the administration of an excessive number of drugs" [13].

Table 4: Drug categories prescribed

\begin{tabular}{lll}
\hline Category of drugs prescribed & Number of drugs & Percentage \\
\hline $\begin{array}{l}\text { Drugs acting on respiratory tract } \\
\text { Drugs acting on gastrointestinal }\end{array}$ & 226 & 20.3 \\
tract including PPI (GIT) & 208 & 18.43 \\
$\begin{array}{l}\text { Antimicrobial drugs } \\
\text { Drugs acting on cardiovascular }\end{array}$ & 192 & 17.02 \\
$\begin{array}{l}\text { system } \\
\text { Analgesics and anti-inflammatory }\end{array}$ & 105 & 10.99 \\
drugs & & \\
Vitamins, minerals & 95 & 9.30 \\
Endocrine system & 90 & \\
Drugs acting on central nervous & 54 & 8.42 \\
system & & 7.97 \\
Diuretics & 25 & 4.78 \\
Others (hematinic, etc.) & 9 & \\
Total & 1128 & 2.2 \\
\hline
\end{tabular}

Table 5: Potentially inappropriate medication

\begin{tabular}{ll}
\hline Name of drug & Number \\
\hline Antispasmodic-anticholinergics & 22 \\
Antihistaminics & 8 \\
Sedatives & 7 \\
H2 blocker & 2 \\
NSAIDs & 2 \\
Total & 41 \\
\hline
\end{tabular}


In the current study, a total of 1128 drugs were prescribed in 200 prescriptions, accounting to average 5.64 number of drugs per prescription. About $38.5 \%$ of total prescriptions had drugs more than 5 drugs, while $61 \%$ had five or less number of drugs. About $56.2 \%$ of geriatric are reported to receive six or more medication (polymedication) in one study [14]

Our results reveal that polypharmacy conducted on medical OPD patients is prevalent in elderly population. However, higher percentage of polymedication has been reported in some studies but mostly related to inward patients as hospitalized patient need more medication in view of their clinical condition [15]. The polypharmacy can be overcome by increasing awareness among prescribing physicians about adverse effects.

Maximum drugs prescribed were from respiratory system (21.1\%), followed by GIT (19\%), antimicrobials (14.9\%), cardiovascular $(11.8 \%)$, NSAIDs $(10.8 \%)$, and vitamins $(8.1 \%)$. Almost similar trend of prescribing has been reported in the past in Indian set up $[8,14,16]$. However, study from developed country showed cardiovascular drugs, diuretics, and psychotropic drugs accounted for $64 \%$ of all drug prescriptions, but these results pertained in population comprised 75 years or above [17]

Alterations in physiological functions, pharmacokinetic and dynamic functions with advancing age make this population more prone to deleterious effects of inappropriate prescribing. In the present study, 41 drugs $(20.5 \%)$ in patients were potentially inappropriate drugs based Beers criteria and belonged mostly to anticholinergic, antihistaminic, sedatives, and NSAIDs. Anticholinergic is known to cause urinary retention, visual disturbances, and dryness of mouth. Antihistaminic and antianxiety sedatives do lead to prolonged hangover may prove hazardous in this group of population and sometime even may result in fall. Inappropriate NSAIDs are responsible for acid peptic disease. Chitra et al., 2017 [16], have also shown PIM in 35.5\% in geriatric group.

\section{CONCLUSIONS}

The current study has shown that polypharmacy in medical OPD geriatric population is prevalent and 34\% received six or more medications. FDCs accounted for 10\%. Inappropriate use of medicine was seen in $20.5 \%$. Brand drugs were mostly prescribed, Maximum drugs prescribed were from respiratory system, followed by GIT and antimicrobials, cardiovascular, and NSAIDs. Results of current trial suggest that polypharmacy issue needs to be redressed, application of Beers criteria to avoid inappropriate prescribing, increasing awareness about polypharmacy should be promoted. Generic drugs usage can be further strengthening Jan Aushadhi outlets.

\section{AUTHORS' CONTRIBUTIONS}

Dr. Kanika conceived the research idea of research work, collected, analyzed, interpreted the data, and wrote the manuscript, while Dr. Vijay Khajuria supervised, reviewed, and edited the manuscript.

\section{CONFLICTS OF INTEREST}

Authors declared no conflicts of interest related to study.

\section{AUTHORS' FUNDING}

Authors did not receive any funding for the research.

\section{REFERENCES}

1. Momin TG, Pandya RN, Rana DA, Patel VJ. Use of potentially inappropriate medications in hospitalized elderly at a teaching hospital: A comparison between Beers 2003 and 2012 criteria. Indian J Pharmacol 2013;45:603-7.

2. United Nations Department of Economic and Social Affairs, Population Division. World Population Prospects (2008 Revision); 2008. Available from: http://www.esa.un.org/unpp/index.asp?panel=2.

3. Hayes BD, Klein-Schwartz W, Barrueto F Jr. Polypharmacy and the geriatric patient. Clin Geriatr Med 2007;23:371-90.

4. The State of Health and Aging in America 2004-CDC, Merck Institute of Aging and Health and Centers for Disease Control; 2004. Available from: https://www.cdc.gov>aging $>$ pdf $>$ state of aging and health.

5. Woodruff K. Preventing polypharmacy in older adults. Am Nurse Today 2010;5:1. Available from: http://www.americannursetoday.com/ preventing-polypharmacy-in-older-adults.

6. Hajjar ER, Cafiero AC, Hanlon JT. Polypharmacy in elderly patients. Am J Geriatr Pharmacother 2007;5:345-51.

7. By the 2019 American Geriatrics Society Beers Criteria ${ }^{\circledR}$ Update Expert Panel. American Geriatrics Society 2019 updated AGS Beers Criteria $^{\circledR}$ for potentially inappropriate medication use in older adults. J Am Geriatr Soc 2019;67:674-94.

8. Veena DR, Padma L, Patil S. Drug prescribing pattern in elderly patients in a teaching hospital. J Dent Med Sci 2012;1:39-42.

9. Oztürk GZ, Ardiç C, Toprak D. Frequency of polypharmacy and use of potentially inappropriate medications in the elderly. Turk J Geriatr 2017;20:296-5.

10. Bhaveshaikh N, Sukumaran S, Vyas U. Drug prescribing patterns in elderly patients in a tertiary level hospital. Int J Basic Clin Pharmacol 2017;6:759-64.

11. Khjauria V, Tandon VR, Rani N, Gilllani Z, Gupta S, Choudhary S, et al. Profile of adverse drug reactions with fixed drug combinations: How big is the problem? JK Sci 2015; 17:33-7.

12. Masnoon N, Shakib S, Kalisch-Ellett L, Caughey GE. What is polypharmacy? A systematic review of definitions. BMC Geriatr 2017; 17:230.

13. World Health Organization. A Glossary of Terms for Community Health Care and Services for Older Persons. In Aging and Health Technical Report. It is Public Health and Economic Issue. Geneva: World Health Organization; 2004.

14. Nataraj GR, Bharathi DR. A study on prescribing pattern in geriatric patients. Asian J Pharm Clin Res 2019;12:120-3.

15. Jhaveri BN, Patel TK, Barvaliya MJ, Tripathi CB. Drug utilization pattern and pharmacoeconomic analysis in geriatric medical inpatients of a tertiary care hospital of India. J Pharmacol Pharmacother 2014;5:15-20

16. Chitra B, Senthilvel N, Sowmya R, Sathyan S, Srisha R. A study on prescribing pattern of drugs in geriatrics using beers criteria at a private corporate hospital. Int J Pharm Sci Res 2015;6:4810-25

17. Kruse W, Rampmaier J, Frauenrath-Volkers C, Volkert D, Wankmüller I, Micol W, et al. Drug-prescribing patterns in old age. A study of the impact of hospitalization on drug prescriptions and follow-up survey in patients 75 years and older. Eur J Clin Pharmacol 1991;41:441-7. 